\title{
The impact of gamification on students learning engagement
}

\author{
Firas Layth Khaleel ${ }^{1}$, Noraidah Sahari Ashaari ${ }^{2}$, Tengku Siti Meriam Tengku Wook ${ }^{3}$ \\ ${ }^{1}$ Electronic Computer Center, Tikrit University, Iraq \\ ${ }^{2,3}$ Faculty of Information Science and Technology, Universiti Kebangsaan Malaysia, Malaysia
}

\begin{tabular}{l}
\hline Article Info \\
\hline Article history: \\
Received Dec 9, 2019 \\
Revised Mar 9, 2020 \\
Accepted Mar 30, 2020 \\
\hline Keywords: \\
Game elements \\
Game mechanic \\
Gamification \\
Motivation \\
Programming language \\
\hline
\end{tabular}

\begin{abstract}
Gamification is to use game elements in a non-game context to increase engagement between human and computer, on the other hand, to encourage in-demand for good behaviors in learning. This research tried to increase student engagements in learning by conducted Gamification technique especially in difficult subjects such as Programming Language courses. The previous work was shown that students dropped, failed, or withdrew from the course at rates of between $35 \%$ and $50 \%$. Therefore the main objective of this study is to increase student engagements in learning programming subject, and also to measure the impact of game elements on student's engagements. Finally, the findings have shown the score of game elements that have a good effect on student's engagement in the experiment group.
\end{abstract}

Copyright $@ 2020$ Institute of Advanced Engineering and Science. All rights reserved.

\section{Corresponding Author:}

Firas Layth Khaleel,

Electronic Computer Center,

Tikrit University,

Salah Din, Tikrit city, Alqadisiya, Box Mail Office (42), Iraq.

Email: Firas_layth@tu.edu.iq

\section{INTRODUCTION}

Student engagement refers to the degree of attention, curiosity, interest, optimism, and ardour that college students exhibit when they are getting to know or being taught, which extends to the stage of motivation they have to study and growth in their education [1]. There are numerous techniques that can amplify the engagement of the user. Competition is another approach that can be used in corporations gamification as a accurate characteristic [2]. Gamification can facilitate motivation which brings about the engagement of users, resulting in higher overall performance and alternate of behavior [3]. Consequently, [4-7] elucidated that an strategy which can effortlessly amplify the engagements and applied in an exciting manner (such as games like elements) ought to be adopted in gaining knowledge of difficult subjects. Gamification refers to the use of recreation factors in a non-game context to expand engagement between human beings and computer systems and to clear up troubles correctly [8-14].

In [15] defined that Gamification can be notion of as the use of portions of games to motivate learners, however the real definition of Gamification includes using game-based mechanics, aesthetics, and recreation questioning to have interaction people, inspire action, promote learning, and remedy problems. G. Zichermann in [16] described Gamification as a method of game questioning and recreation mechanics that engages users and solves problems.

Gamification is a fundamentally portion of an application since it can guarantee the adequacy of its utilization, as illustrated within the comes about of [17]. Inside the learning environment, the benefits of Gamification components cannot be overlooked since the most objective is to extend client adequacy and understanding inside a fun and agreeable learning in this manner yielding tall client execution. Based on the comes about of [17], this investigate tries to fathom the issue through a Gamification approach to confirm the viability of applying a Gamification approach to understudies particularly in hardest subjects such as Programming Dialect courses (i.e. HTML, CSS, SQL, Visual Essentials, C++/Java, and Machine Dialect). 
Programming Dialect courses have tall disappointment rates concurring to [18-22]. As of now, their a few analysts are inquisitive about gamification, which would make a locks in environment in learning persistently [2]. Gamification's principal objective is to upgrade the engagement of clients by receiving game-like procedures as scoreboards and personalized input and it's by and large affect on the organization [2].

\section{LITERATURE REVIEW}

Gamification is a pioneering and innovative approach that tells how the organizations have embedded these strategies in their software program to boom the pupil's engagement [2]. Thom et al. [17], used a new method that omits gamification from social networks can lead to the subsequent effects: (1) decreased consumer engagement; (2) decreased user participation; and (3) decreased scholar achievement. In different words, not the use of gamification in designing an software can lead to an unsuccessful utility, especially regarding person engagement and studying. For example, Table 1 provides the consequences before and two weeks after omitting gamification, along with the points gadget element, in a social network service.

Gamification is an integral part of an application as it can make sure effectiveness, as demonstrated in the consequences proven in Table 1, which show as an instance a decrease in images from 4.502 to 2.926 and a lower in users of these photographs from 2.6 to 1.7. In the educational field, the blessings of gamification elements cannot be left out because the main purpose is to increase person effectiveness and understanding within a a laugh and enjoyable mastering environment, thereby yielding excessive person performance. This indicates the impact of the elimination of the points system as a gamification function inside a social networking system could result in a widespread negative impact on the consumer pastime of the site, and [15] suggested that contribution of content significantly reduced after the deactivation of the points machine.

Table 1. Results of omitting the points system, after two weeks [15]

\begin{tabular}{lcc}
\hline & Points deployed total (\#/user) & Points removed total (\#/user) \\
\hline Photo & $4502(2.6)$ & $2926(1.7)$ \\
Lists & $1277(1.0)$ & $780(0.64)$ \\
Profile comment & $8983(5.5)$ & $4056(2.5)$ \\
Photo comment & $2598(2.9)$ & $1348(1.5)$ \\
List comment & $1770(2.5)$ & $873(1.2)$ \\
\hline
\end{tabular}

Gamification is a translation of game elements in non-game contexts [23] that can be used in several areas, such as education and learning, health, and sciences (e.g., biology, http://eterna.cmu.edu/) [24]. Some success uses of gamification are explained in the following subsections. In addition to using a game element (gamification) to applications, specifically mobile applications can lead to increased user engagement. For example, a mobile application to help new undergraduate students familiarize themselves with the university facilities is an important tool that can be given to the students [25]. However, the following considerations must be considered in deciding such applications 1) adding an element that makes the application easier to use even for students who are inexperienced in modern technology; 2) striking a balance between being user-friendly and fun.

\section{METHOD}

This segment mentioned the layout a part of gamification internet site by using carried out unified modeling language. Unified modeling language (UML) is a general-purpose, design, developmental, modeling language within the area of Software Engineering that is supposed to provide a standard way to visualize the design of a machine [26-30]. It is essential to distinguish between the UML model and the set of diagrams of a gadget. A diagram is a partial graphical representation of the version of a gadget. The set of diagrams need now not absolutely cowl the model. Deleting a diagram will no longer trade the version. The version can also also contain documentation that drives the version elements and diagrams (such as written use cases).

UML diagrams constitute two unique perspectives of a gadget version [27-30]: (1) static (or structural) view: this emphasizes the static structure of the machine using objects, attributes, operations, and relationships. The structural view includes class diagrams and composite structure diagrams; and (2) dynamic (or behavioral) view: this emphasizes the dynamic behavior of the gadget with the aid of showing collaborations among gadgets and adjustments to the internal states of items. This view includes, use case diagrams and interest diagrams. 


\subsection{Use-case diagram}

Figure 1 below, illustrates the Use-Case Diagram for the overall process of designing the gamification website. The actor provided is a simple user who interacts with all 13 cases. In order to completely draw the Use-Case Diagram, the steps that users must follow based on the Use-Case Diagram such as (1) all students must register their information (such as username and password) by clicking on "Signup"; (2) students must enter their login information (Student ID) along with their password and click "Sign In"; (3) on the Profile page, students can see their personal information, Stage, Level and Points, and they can modify or update their information by clicking "Modify Profile"; (4) all students can see the general map of gamification gameplay, including the concept levels for each stage (Fundamental Programming) by clicking on "Gamification"; and (5) students can then answer questions, and once they feel that they have understood the level of concepts, explanations, and exercises very well, they can click on "Submit" to see their results on the Top 10 or Leaderboard. Students can also see their results in a table consisting of their ID, First name, Mark, Stage, Level points, Stars, Competence, Time, and Assessment time, as well as through a graphical report plus an Achievement (Badge) for all questions.

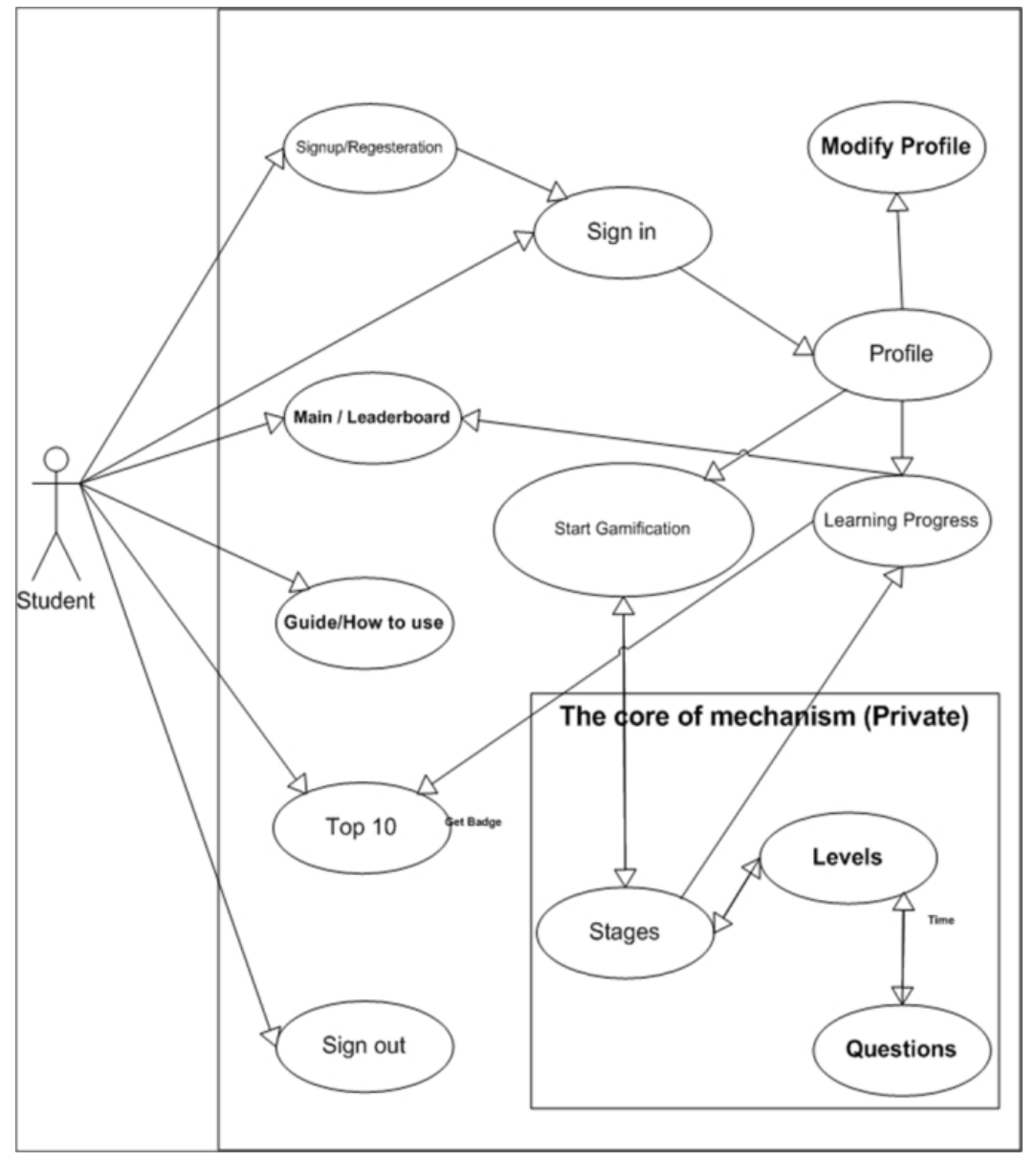

Figure 1. Use-case diagrams for gamification application

\subsection{Active diagram}

Active diagrams are used to model a process or a task and to describe the system function represented by the Use-Case Diagram. It is mostly useful to model business activities in the early stage of a project. Therefore, this diagram is used to give an idea of the main process involved in the prototype system. Figure 2 shows the Active Diagram for the overall process of the gamification application.

The main reason that leads to this study was to explore the effectiveness of gamification techniques on student's engagement in learning the Java language. The components of gamification framework were produced and selected based on previous work with experts' perspectives. The experiment was conducted to address the following hypotheses based on effectiveness evaluation: 
- Hypothesis H01: There is no significant difference between the pre- and post-test average scores for the experimental group.

- Hypothesis H02: There is no significant difference between the pre- and post-test average scores for the control group.

- Hypothesis H03: There is no significant difference in overall results between the sample participants who learned using the gamification application and the ones that learned via the conventional teaching method (control group).

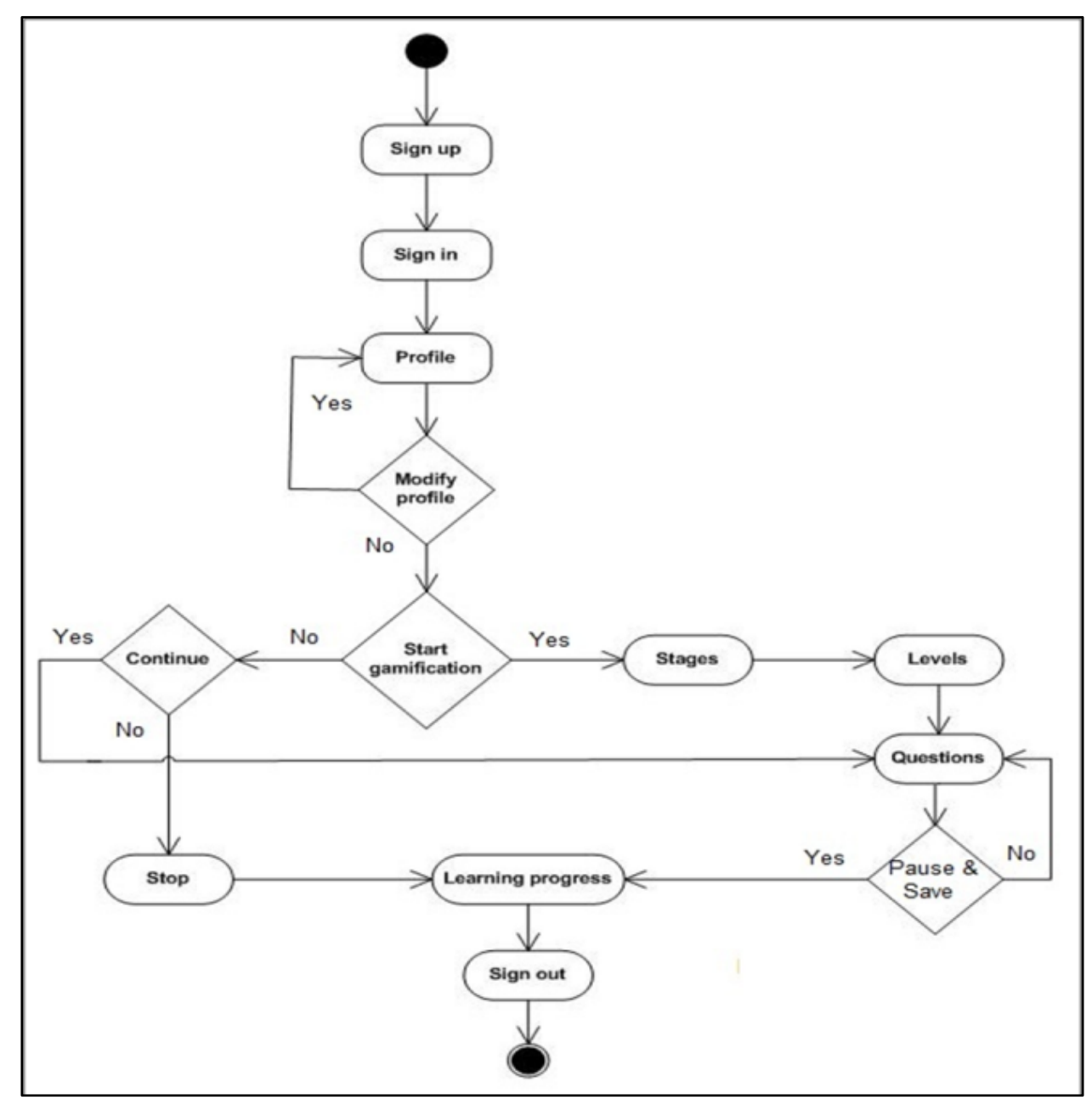

Figure 2. Active diagram for gamification application

On the other hand of the experiment, the following hypotheses based on engagement evaluation: - Hypothesis H04: There is no engagement in students learning of experimental group in using point game elements.

- Hypothesis H05: students' of the experimental group do not like to see their result online (in real time).

- Hypothesis H06: students' of the experimental group do not accept for all game elements as a factor to increase the engagement.

The sampling of engagement evaluation of gamification application was conducted with 60 students from UKM - FTSM (new students registration in September intake 1(2015/2016). The students were assigned to two groups of 30 students; experimental group $(\mathrm{Eg})$ and control group $(\mathrm{Cg})$ and six IT teachers expert in programming language and one in the game area. Instruments used was engagements evaluation list and the interview schedule which consists of four questions adapted from previous studies [28-30] as explained in Table 2 and also $10 \mathrm{MCQ}$ questions for the same evaluation. All the items were adapted from previous studies. 
Table 2. The interview questions

\begin{tabular}{ll}
\hline No & \multicolumn{1}{c}{ Questions } \\
\hline 1 & $\begin{array}{l}\text { Did you continue working after earning } 300 \text { points (Stage one)? } \\
\text { And if so, tell us, why you did so. }\end{array}$ \\
2 & $\begin{array}{l}\text { Did you stop working after earning } 300 \text { points (Stage one)? And } \\
\text { if so, tell us what made you stop working. }\end{array}$ \\
3 & Which game elements did you prefer? \\
4 & Which game elements did not appeal to you? \\
\hline
\end{tabular}

The method of Interviews was conducted in person as a face to face interview in UKM. The interview questions were open end questions and structured the details of interview questions as shown in Table 2. The instrument was in this study conducted using MCQ questions, distributed by self-administration to students. Also, this study adapted a mixed research method approach known as the convergent design method [30]. Convergent design method when the researcher conducts qualitative and quantitative studies, in the same phase of the research. The qualitative approach refers to the open-ended questions were administered and then analyzed based on content analysis. The quantitative approach is the data about the activity of students answer the $10 \mathrm{MCQ}$ questions then analyzed statistically using paired and independent t-test analysis in SPSS software. In University Kebangsaan Malaysia - FTSM, there are three kinds of new students such as (STPM, STAM, Matriculation 1, Matriculation 2, and Matriculation 3). STPM, STAM and Matriculation 1, these kinds of new students, they never take any programming language course before, that is lead to select 60 students from them as experimental and control groups.

\section{RESULT AND DISCUSSION}

This section will discuss the findings regarding engagements evaluation as below.

\subsection{Students' effectiveness}

To evaluate the hypothesis as mentioned in the previous section, the result of students in experiment and control groups are close in the pre-test. But in post-test, the student in the experiment group have high result than another group, that indicates to increase the knowledge of students after using gamification application, as shown in Tables 3-6.

Table 3. Paired t-test for all groups

\begin{tabular}{cccccc}
\hline Pre - Post & Mean & Std. Deviation & t & Df & Sig. (2-tailed) \\
\hline Eg & 3.120 & .653 & 26.168 & 29 & .000 \\
$\mathrm{Cg}$ & 1.930 & .391 & 27.068 & 29 & .000 \\
\hline
\end{tabular}

Table 4. Mean score for all groups

\begin{tabular}{cccc}
\hline & & Mean & Std. Deviation \\
\hline \multirow{2}{*}{ Eg } & Pre-Eg & 1.49 & .455 \\
& Post-Eg & 4.61 & .438 \\
$\mathrm{Cg}$ & Pre-Cg & 1.50 & .509 \\
& Post-Cg & 3.43 & .456 \\
\hline
\end{tabular}

Table 5. Results of the independent t-test for group statistics (Eg, Cg)

\begin{tabular}{ccccc}
\hline & Use Gamification & Mean & Std. Deviation & Std. Error Mean \\
\hline \multirow{2}{*}{ Post-test } & Eg & 4.61 & .438 & .080 \\
& $\mathrm{Cg} 1$ & 3.43 & .456 & .083 \\
\hline
\end{tabular}

Table 6. Results of the independent t-test between $\mathrm{Eg}$ and $\mathrm{Cg}$

\begin{tabular}{ccccc}
\hline & $\mathrm{t}$ & $\mathrm{df}$ & Sig. (2-tailed) & Std. Error Difference \\
\hline Pre-test & .080 & 58 & .936 & .125 \\
Post-test & 10.224 & 58 & .000 & .115 \\
\hline
\end{tabular}

According to Tables 3 and 4, the paired-t-test shows that there is a significant difference in the scores for pre-test $(\mathrm{Eg})(\mathrm{Mean}=1.49, \mathrm{SD}=.455)$ and post-test $(\mathrm{Eg})(\mathrm{Mean}=4.61, \mathrm{SD}=.438)$ conditions: $t(29)=26.168, p<0.0001$ for the experimental group. This means that there is a significant change in knowledge using conventional teaching method and using the Gamification application that results in 
the rejection of $\mathrm{H} 01$. H02 was also rejected. There was a significant difference in the scores for pre-test $(\mathrm{Cg})$ (Mean=1.50, SD=.509) and post-test $(\mathrm{Cg} 1)($ Mean=3.43, $\mathrm{SD}=.456)$ conditions: $\mathrm{t}(29)=27.068, \mathrm{p}<0.0001$ for control group 1. This indicates that there is a significant change in knowledge gain for $\mathrm{Cg}$, who used conventional teaching methods only and had never learned a programming language before. The results of the independent t-test for $\mathrm{H} 03$ are presented in Tables 5 and Table 6; there was a significant difference in the post-test score of the Eg group (Mean=4.61, $\mathrm{SD}=.438$ ) and $\mathrm{Cg}$ group (Mean=3.43, $\mathrm{SD}=.456$ ) conditions: $\mathrm{t}(58)=10.224, \mathrm{p}<0.0001$. This means that learning using the Gamification website has been proven to be effective in increasing the students' engagements when learning programming language concepts.

\subsection{Students engagement}

All students in the experiment group continue to do working after earning 300 points in the first stage. Also, they like to continue until achieving the goal of gamification application that lead to rejecting of H04 as shown in Table 7. On the other hand of students' perception, all students like to see their result online in real time that is lead to increase students' engagements and motivation in learning, that lead to rejecting of H05. Also the perception of students' acceptance over all game elements used in gamification website, as shown in Table 7. According to Table 7, the students' percentage of acceptance game element in engagement such as Points, Top10 and Badge has 100 percent as labeled in Figures 1 and 2, which lead to rejecting of $\mathrm{H} 06$.

Table 7. Game elements

\begin{tabular}{lll}
\hline Tasks / Functionality & Game elements & Percentage of acceptance in engagement \\
\hline Achievement & Points/ Scoring system/ Stars & 100 \\
Virtual gifts & Badge & 100 \\
Reward schedules & Top 10 & 100 \\
& Leaderboard & 100 \\
Status & Real-time Result & 100 \\
& Report & 91.34 \\
& Dashboard & 88.65 \\
& Percentage of Competency & 82.73 \\
Real-time & Progress Bar & 89.67 \\
& Stage & 85.92 \\
\multirow{2}{*}{ Profiles } & Level & 88.48 \\
& Countdown & 70.27 \\
& Information in profile & 80.83 \\
\hline
\end{tabular}

\subsection{Students feedback}

A sample of the participants' comments is now presented.

- Participant 1: "I will continue doing the answer MCQ until I get all Badge."

- Participant 2: "300 hundred points not enough; I'm trying to reach the 1800 points with the lowest duration time and some rounds."

- Participant 3: "It's good for us to keep try until we find the right answer that is lead to increase the engagements in learning."

- Participant 4: "Sometimes I like to learn more about a programming language, but unfortunately I faced a problem with the understanding the concepts."

In conclusion, there is a positive level of engagements in student learning programming language Tables 3-6. Similarly to [29-30], found positive effects on the engagement of students toward the gamified learning activities and also a high improvement in learning outcomes as presented in Tables 3-6.

\section{CONCLUSION}

This research tried to solve the problem through a Gamification technique to verify the engagement of applying a Gamification technique to students especially in difficult subjects such as programming language courses. Applying game elements in the main page of the website such as Top 10 and Leaderboard to make students see their result in real time. That is events lead to increase students engagements and motivation in learning. Finally, the findings of students in the experiment group are highest that other group. Also, all game elements have a positive effect on student's engagement on experiment group and that have high acceptance based on students evaluation. 


\section{ACKNOWLEDGEMENTS}

This work is supported by Universiti Kebangsaan Malaysia/Faculty of Information Science and Technology-Research Center for Software Technology and Management-Multimedia Software and Usability Research Group. Grant No. is FRGS/ 2/ 2014/ ICT05/ UKM/ 02/ 1. JPT-KPM ID: 68910-78756.

\section{REFERENCES}

[1] A. Sabu., "Students engagements in Education Reform," [Online] Available: http://edglossary.org/studentengagement/, 2016.

[2] A. Aziz, A. Mushtaq, and M. Anwar, "Usage of gamification in enterprise: A review," International Conference on, Communication, Computing and Digital Systems, pp. 249-252, 2017.

[3] P. Sureephong, K. Puritat, and S. Chernbumroong, "Enhancing user performance and engagement through gamification: Case study of aqua republica," 10th International Conference on, Software, Knowledge, Information Management \& Applications, pp. 220-224, 2016.

[4] M. Chang, "Web-Based Multiplayer Online Role Playing Game (MORPG) for Assessing Students' Java Programming Knowledge and Skills," IEEE International Conference Digital Game and Intelligent Toy Enhanced Learning, pp. 103-107, 2010.

[5] K. Dai, Y. Zhao, and R. Chen, "Research and Practice on Constructing the Course of Programming Language," IEEE 10th International Conference on Computer and Information Technology, pp. 2033-2038, 2010.

[6] P.-H. Tan, C.-Y. Ting, and S.-W. Ling, "Learning difficulties in programming courses: undergraduates' perspective and perception," International Conference on Computer Technology and Development, pp. 42-46, 2009.

[7] H. Tsukamoto, N. Nitta, Y. Takemura, and H. Nagumo, "Work in progress: Analysis of the relationship between teaching contents and motivation in programming education," Proceedings of the IEEE Frontiers in Education Conference, pp. 1-2, 2012.

[8] S. Deterding, D. Dixon, R. Khaled, and L. Nacke, "From game design elements to gamefulness: Defining gamification," Proceedings of the 15th International Academic MindTrek Conference: Envisioning Future Media Environments, pp. 9-15, 2011.

[9] S. Deterding, M. Sicart, L. Nacke, K. O'Hara, and D. Dixon, "Gamification. using game-design elements in nongaming contexts," CHI'11 Extended Abstracts on Human Factors in Computing Systems, pp. 2425-2428, 2011.

[10] F. L. Khaleel, N. S. Ashaari, T. S. Meriam, T. Wook, and A. Ismail, "The study of gamification application architecture for programming language course," Proceedings of the 9th International Conference on Ubiquitous Information Management and Communication, pp. 1-5, 2015.

[11] F. L. Khaleel, N. S. Ashaari, T. S. Meriam, T. Wook, and A. Ismail, "User-Enjoyable Learning Environment Based on Gamification Elements," International Conference on Computer, Communication, and Control Technology, pp. 221-226, 2015.

[12] F. L. Khaleel, N. S. Ashaari, T. S. Meriam, T. Wook, and A. Ismail, "The Architecture of Dynamic Gamification Elements Based Learning Content," Journal of Convergence Information Technology, vol. 11, no, 3, pp. 164-177, 2016.

[13] F. L. Khaleel, N. S. Ashaari, T. S. Meriam, T. Wook, and A. Ismail, "Programming Learning Requirements Based on Multi Perspectives," International Journal of Electrical and Computer Engineering, vol. 7, pp. 1-8, 2017.

[14] F. L. Khaleel, T. S. M. T. Wook, N. S. Ashaari, and A. Ismail, "Gamification Elements for Learning Applications," International Journal on Advanced Science, Engineering and Information Technology, in press, vol. 6, no. 6, pp. 868-874, 2016.

[15] K. M. Kapp, "The Gamification of Learning and Instruction Fieldbook," Ideas Into Practice: John Wiley \& Sons, 2013.

[16] G. Zichermann and C. Cunningham, "Gamification by design: Implementing game mechanics in web and mobile apps:," O'Reilly Media, Inc., 2011.

[17] J. Thom, D. Millen, and J. DiMicco, "Removing gamification from an enterprise SNS," Proceedings of the ACM 2012 conference on Computer Supported Cooperative Work, pp. 1067-1070, 2012.

[18] A. Robins, J. Rountree, and N. Rountree, "Learning and teaching programming: A review and discussion," Computer Science Education, vol. 13, no. 2, pp. 137-172, 2003.

[19] A. Adorjan and I. Friss de Kereki, "Multiple Intelligence approach and competencies applied to Computer Science 1," IEEE Frontiers in Education Conference, 2013 2013, pp. 1170-1172.

[20] P. Kinnunen and L. Malmi, "Why students drop out CS1 course?," Proceedings of the second international workshop on Computing education research, pp. 97-108, 2006.

[21] J. Bennedsen and M. E. Caspersen, "Failure rates in introductory programming," ACM SIGCSE Bulletin, vol. 39, pp. 32-36, 2007.

[22] A. P. Ambrósio, F. M. Costa, L. Almeida, A. Franco, and J. Macedo, "Identifying cognitive abilities to improve CS1 outcome," Frontiers in Education Conference, pp. F3G-1-F3G-7, 2011.

[23] B. M. Good, S. Loguercio, M. Nanis, and A. Su, "Genegames. org: High-Throughput Access to Biological Knowledge and Reasoning through Online Games," IEEE Second International Conference on, Healthcare Informatics, Imaging and Systems Biology, pp. 145-145, 2012.

[24] L. Von Ahn and L. Dabbish, "Labeling images with a computer game," Proceedings of the SIGCHI conference on Human factors in computing systems, pp. 319-326, 2004.

[25] F. L. Khaleel., Ashaari, N. S., and Wook, T. S. M. T., "Designing Usable Gamified Programming Learning Website," 7th International Conference on IEEE Electrical Engineering and Informatics, pp. 164-169, 2019. 
[26] F. L. Khaleel., Mohanad Layth Khaleel, Yasser Alsalam, Mohammed Abdulaziz Alsubhi, and Abdullatif Saleh Alfaqiri, "Smart Application Criterion based on Motivation of Obese People, "Electrical Engineering and Informatics, pp. 530-535, 2019.

[27] Shivan Qasim Ameen, F. L. Khaleel, "Wireless Mesh Networks Based on MBPSO Algorithm to Improvement Throughput," International Journal of Electrical and Computer Engineering, vol. 8, no. 6, pp. 4374-4381, 2018.

[28] F. L. Khaleel, "Recruitment and Job Search Application," PhD Thesis. Universiti Utara Malaysia, 2011.

[29] F. L. Khaleel., Ashaari, N. S., Wook, T. S. M. T., and Ismail, A., "Gamification-based learning framework for a programming course," 6th International Conference on IEEE Electrical Engineering and Informatics, pp. 1-6, 2017.

[30] F. L. Khaleel, Ashaari, N. S., Wook, T. S. M. T., and Ismail, A.,. "Methodology for developing gamification-based learning programming language framework," 6th International Conference on IEEE Electrical Engineering and Informatics, pp. 1-6, 2017. 